\title{
Evaluation of radiosonde humidity sensors at low temperature using ultralow-temperature humidity chamber
}

\author{
Byung Il Choi ${ }^{1}$, Sang-Wook Lee ${ }^{1}$, Sang-Bong Woo ${ }^{1}$, Jong Chul Kim ${ }^{1}$, Yong-Gyoo Kim ${ }^{1}$, and \\ Seung Gu Yang ${ }^{2}$ \\ ${ }^{1}$ Korea Research Institute of Standards and Science, Daejeon, Korea \\ ${ }^{2}$ Jinyang Industrial, Ansung, Korea \\ Correspondence: Byung Il Choi (cbi@kriss.re.kr)
}

Received: 7 February 2018 - Revised: 6 August 2018 - Accepted: 8 August 201 - Published: 23 August 2018

\begin{abstract}
Accurate measurements of temperature and water vapor in the upper-air are of great interest in relation to weather prediction and climate change. Those measurements are mostly conducted using radiosondes equipped with a variety of sensors that are flown by a balloon up to lower stratosphere. Reference Upper Air Network (GRUAN) has identified water vapor pressure as one of the most important measurands and has set an accuracy requirement of $2 \%$ in terms of the mixing ratio. In order to achieve the requirement, many errors in the humidity measurement such as a temperature dependency in sensing characteristics including measurement values and response time need to be corrected because humidity sensors of radiosondes pass through low-pressure $(1 \mathrm{kPa})$ and low-temperature $\left(-80^{\circ} \mathrm{C}\right)$ environments in the upper-air. In this paper, the humidity sensing characteristics of Jinyang radiosonde sensors in relation to temperature dependencies were evaluated at low temperature using a newly developed ultralow-temperature humidity chamber. The sensitivity characteristic curve of the radiosonde sensors was evaluated down to $-80^{\circ} \mathrm{C}$, and the calibration curves of the humidity sensor and the temperature sensor were obtained. The response time of humidity sensor slowly increased from 52 to $116 \mathrm{~s}$ at the temperature from 20 to $-40^{\circ} \mathrm{C}$, respectively, and then rapidly increased to almost one hour at $-80^{\circ} \mathrm{C}$. Those results will help to improve the reliability of the upper-air observation data.
\end{abstract}

\section{Introduction}

The measurement of upper-air temperature and humidity plays an important role in various fields, e.g., addressing global warming, forecasting weather, and ensuring aviation safety. In general, the measurement is performed by launching a radiosonde equipped with temperature and humidity sensors, up to an altitude of $30 \mathrm{~km}$, to gather and send data back to the ground. However, upper-air measurements tend to have much poorer reliability than ground-based measurements due to the extreme environmental conditions, e.g., low air temperatures down to $-80^{\circ} \mathrm{C}$ or less, low pressure $(1 \mathrm{kPa})$, and high solar radiation. The 8th international comparison of radiosonde (Nash et al., 2011) hosted by WMO reported that the measurement discrepancy among temperature sensors was up to $1.7^{\circ} \mathrm{C}$, and the discrepancy was even larger for humidity sensors, up to $30 \% \mathrm{RH}$. Given that the global warming trend has been equivalent to about a $1{ }^{\circ} \mathrm{C}$ rise in the past century, the accuracy levels of the current upperair temperature measurement systems are insufficient to effectively address global warming issues. The reason for the inaccuracy is that, with regard to temperature measurement, the heating effect of solar radiation is not properly compensated, and, for humidity measurement, the sensing characteristics of humidity sensors are temperature dependent. Therefore, it is necessary to evaluate radiosonde sensors using an ultralow-temperature humidity chamber (UTHC) which enables more reliable measurements as well as the traceability of measurements to the upper air conditions. This effort to develop a measurement traceability-embedded UTHC and evaluate radiosonde sensors is in line with the current trend of improving reliability in meteorological measurements. The 
WMO executed a mutual recognition agreement (MRA) with the BIPM (Bureau International des Poids et Mesures) to ensure measurement traceability to the International System of Units (SI) (WMO-BIPM, 2010).

Furthermore, according to the measurement standards set by the WMO's Reference Upper Air Network (GRUAN), the uncertainty of measurement is specified not only for temperature and humidity measurement but also for wind speed and pressure measurement. These efforts also show that the global trend in meteorological measurements is moving towards improving reliability. GRUAN named humidity as one of the most important upper-air measurement items, and has mandated measurement uncertainty for it is below $2 \%$ in term of the water vapor mixing ratio (GCOS, 2013).

In an effort to allow the low-temperature calibration of radiosondes specialized in upper-air measurement, MIKES in Finland developed a UTHC (Sairanen et al., 2015) that met the uncertainty requirement of the GRUAN which is $2 \%$ in terms of the mixing ratio. Its UTHC was based on a hybrid humidity generator principle (Mayer et al., 2008), in which the carrier gas passing through a saturator and a zero gas supplier mixed in a controlled way for the humidity generation. In this regard, it allows a fast humidity change by controlling the mixing ratio and thus can be useful for studying dynamic responses of humidity sensors in addition to the calibration at static states. However, the use of the zero gas supplier contributed the major uncertainty in the uncertainty of the humidity generation. The KRISS UTHC operates in a two pressure mode which enables a relatively fast humidity change. The major uncertainty factor is the uncertainty by the device under test (DUT) in an effort to validate the humidity generation using an independent hygrometer. A more detailed description on UTHC is being prepared as an independent paper.

\section{Development of ultralow-temperature humidity chamber}

A high precision humidity generator, used as reference standard for humidity, adopts a saturator-based method, where air is saturated under a specific temperature and pressure, and is subsequently transferred to an environment of different temperature and pressure to generate the desired humid air. These methods include a two-temperature method, a two-pressure method, and a combined two-temperature and two-pressure method (Wiederhold, 1997; Choi et al., 2012). The UTHC developed in the present study adopted the twopressure method, and the setup comprises a saturator, a test chamber, and an expansion valve. Here, humid air is generated by using a frost-point generation technique, which uses the saturated water vapor pressure on the surface of the ice in the saturator. Therefore, analytical interpretation of results is allowed along with reliable measurement because the approach generates humidity based on the natural phenomenon regarding condensed material and vapor pressure. The saturator comprises 11 sub-saturators. Each sub-saturator contains a spiral-grooved saturator pipe coated with ice. When dry air travels through this ice-coated pipe, thermal equilibrium is achieved between the ice coating and water vapor, thus giving rise to saturated humid air. The saturated humid air is sent to the test chamber with the pressure change made by the expansion valve. Here, the relative humidity of the test chamber can be changed by adjusting the pressure drop. A test chamber is where radiosonde sensors are placed, and in the present study the authors developed various types of test chambers, e.g., a large-scale test chamber to accommodate up to five module packages of sensors and a smallscale chamber to quickly change relative humidity. Figure 1 shows the main parts of the assembled humidity chamber, i.e., the saturator, test chamber, and expansion valve, along with the photograph of two different test chambers equipped with a radiosonde. The saturator and the test chamber were immersed in the same liquid bath. The expansion valve is used to control the pressure of the saturator and thus control the humidity in the test chamber. The small-scale test chamber was used for the evaluation of sensors in this paper since it provides faster humidity generation. The flow rate through the humidity generator was $1 \mathrm{~L} \mathrm{~min}^{-1}$ and the air speed is not considered for the evaluation of sensors. A dew-point meter (MBW 373LX) is connected serially to the gas outlet of the test chamber.

The generation capacity of the frost-point temperature by the UTHC saturator is -90 to $+50{ }^{\circ} \mathrm{C}$ while the temperature range of the test chamber is -80 to $+50^{\circ} \mathrm{C}$. The maximum pressure of the saturator is $10 \mathrm{MPa}$. Thus, the relative humidity generation capacity of the test chamber is $1 \% \mathrm{RH}$ to $100 \% \mathrm{RH}$ in the temperature range from -80 to $+50{ }^{\circ} \mathrm{C}$. The uncertainty of relative humidity generated by the UTHC is around $1 \% \mathrm{RH}$ in the temperature range from -50 to $50^{\circ} \mathrm{C}$ whereas the uncertainty increases below $-50^{\circ} \mathrm{C}$, reaching $1.3 \% \mathrm{RH}$ at $-60^{\circ} \mathrm{C}$ and $2 \% \mathrm{RH}$ at $-80^{\circ} \mathrm{C}$. The uncertainty value at low temperature is mostly contributed by the effect of adsorption/desorption of moisture on the surface of chamber and tubing line. It could be evaluated by the difference between the frost-point temperature generated by the UTHC and that measured by the chilled-mirror hygrometer.

\section{Evaluation of radiosonde sensor characteristics}

\subsection{Temperature dependence of humidity sensitivity response}

Radiosonde sensor characteristics were evaluated with the UTHC. The sensors tested in the present study were provided by Jinyang Industrial Co., Ltd., who manufactured the radiosonde. The evaluation of humidity sensors was carried out as follows: the humidity sensors were first calibrated at room temperature $\left(20^{\circ} \mathrm{C}\right)$; the temperature of the test chamber was decreased to $-80^{\circ} \mathrm{C}$; and the temperature was in- 


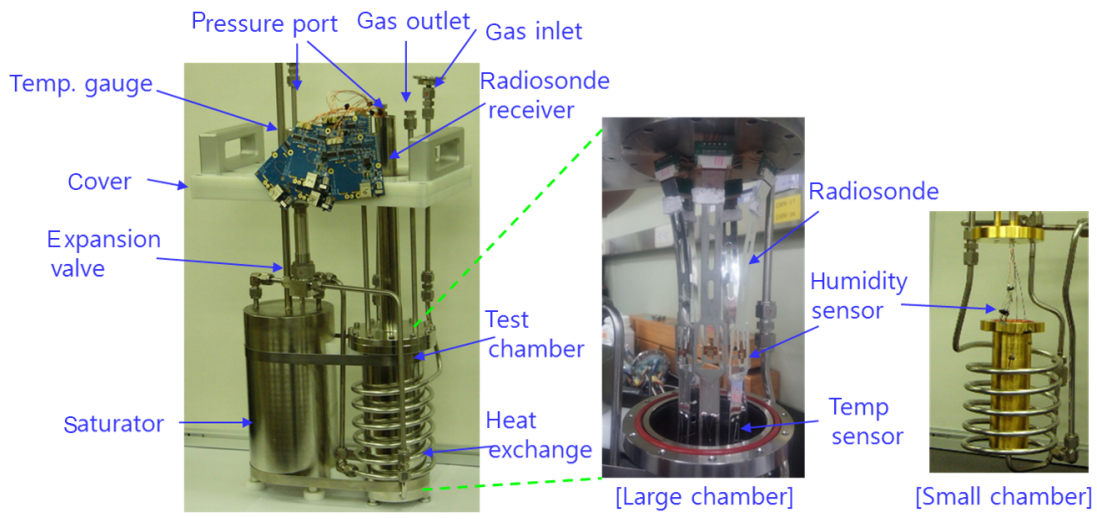

Figure 1. Assembled view and photo of main saturator and test chambers with radiosonde.

creased step by step, i.e., $-80 \rightarrow-70 \rightarrow-60 \rightarrow-40 \rightarrow$ $-20 \rightarrow-1{ }^{\circ} \mathrm{C}$. The relative humidity was changed for the sensor evaluation at each temperature. In order to change the relative humidity in the test chamber, the pressure of the saturator is varied from $800 \mathrm{kPa}$ for low relative humidity to atmospheric pressure $(\sim 100 \mathrm{kPa})$ for high relative humidity while that of the test chamber is fixed at atmospheric pressure. The temperature and the pressure of the saturator and the test chamber were measured by platinum resistance temperature (PRT) sensors and high precision pressure gauges (Proscientific 745), respectively. Both PRTs and pressure gauges are calibrated at KRISS. Figure 2a shows the output values of the analogue to digital converter (ADC) on radiosondes with respect to the capacitance of the thin-film humidity sensor measured during the calibration at roomtemperature $\left(20^{\circ} \mathrm{C}\right)$. Figure $2 \mathrm{~b}$ shows the conversion of the $\mathrm{ADC}$ values to humidity values by the calibration curve obtained by the linear fitting of the ADC values. The ADC values during the calibration at room temperature generally well agree with the linear calibration curve at a mid-range in relative humidity while they slightly deviate from the calibration curve at low (below $10 \% \mathrm{RH}$ ) and high (above $90 \% \mathrm{RH}$ ) relative humidity.

Figures 3 and 4 show results obtained at each investigated air temperature. Those are results of the humidity measurement by two radiosonde sensors (Red and Pink curves) as well as the reference humidity by the generator (Blue curve) and the hygrometer measurement (Green curve) obtained at each investigated air temperature. The reference standard can be either the values by the UTHC or hygrometer. These two values showed essentially no difference from 20 to $-60^{\circ} \mathrm{C}$ while the hygrometer value started to deviate from that of UTHC at lower temperature than $-60^{\circ} \mathrm{C}$. Although these two references may be united at the equilibrium state after a longer observation than several hours, the current difference between two values at -70 and $-80^{\circ} \mathrm{C}$ is about $1.5 \% \mathrm{RH}$. This is because the equilibrium for the adsorption/desorption of water molecules takes a longer time as the temperature is lowered, the surface area of the test chamber is bigger,
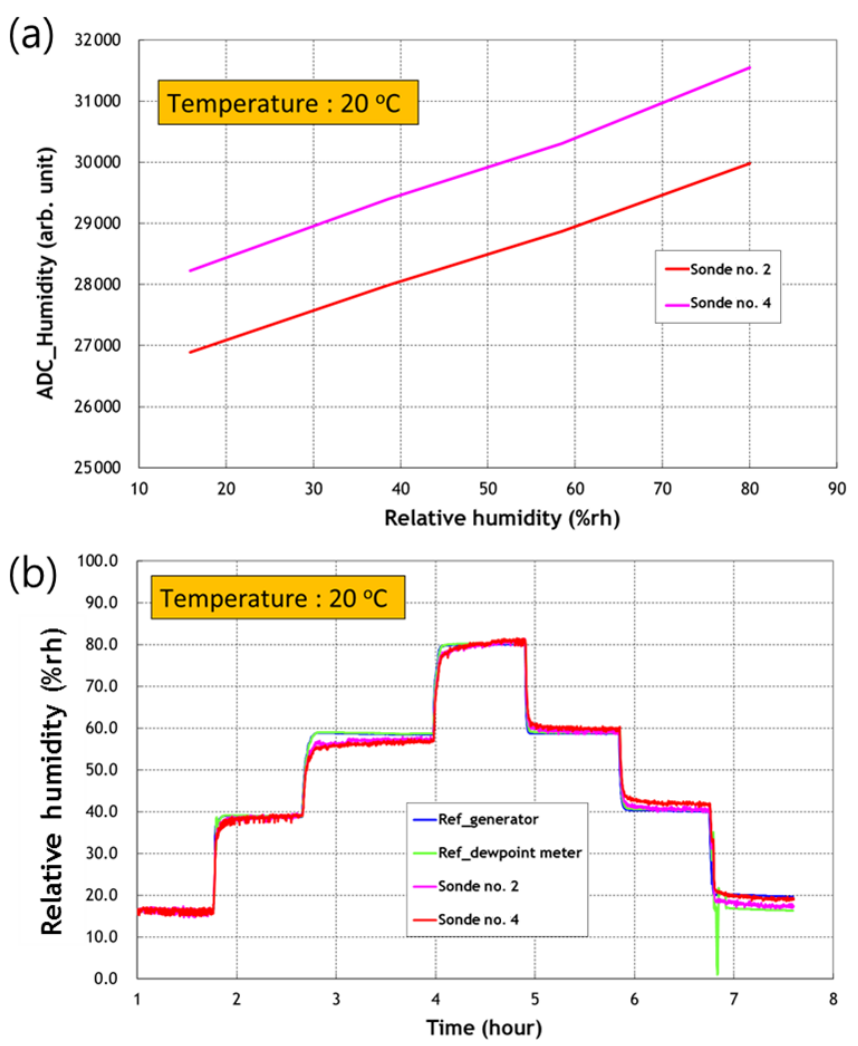

Figure 2. (a) ADC values with respect to the capacitance of radiosonde humidity sensors as a function of relative humidity and (b) the conversion of ADC values to relative humidity by radiosonde humidity sensors (Red and Pink curves) and the reference relative humidity by the generator (Blue curve) and the hygrometer (green curve) at $20^{\circ} \mathrm{C}$.

and/or more humidity sensors are installed. In this regard, the value of the calibrated hygrometer rather than that of the generator is chosen as the reference humidity standard in this work. Down to the temperature of $-20^{\circ} \mathrm{C}$, the humidity measurements showed no significant deviation from the reference standard for humidity, as in the case of the 
(a)

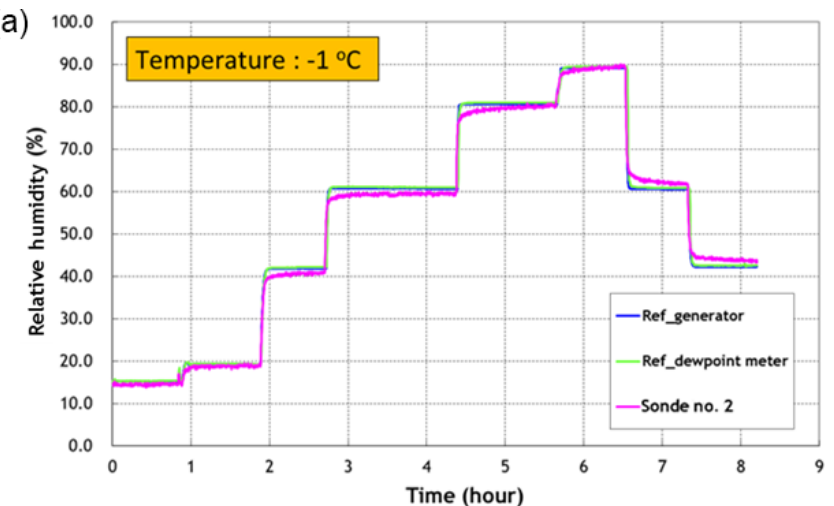

(b)

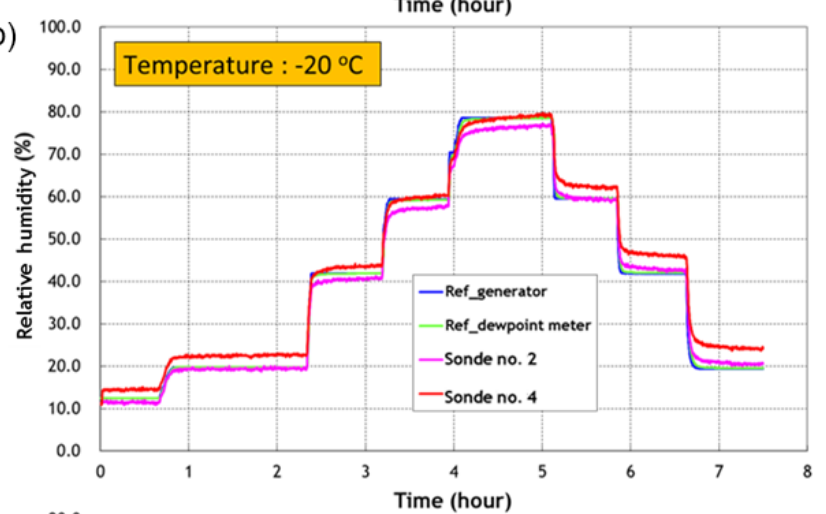

(c)

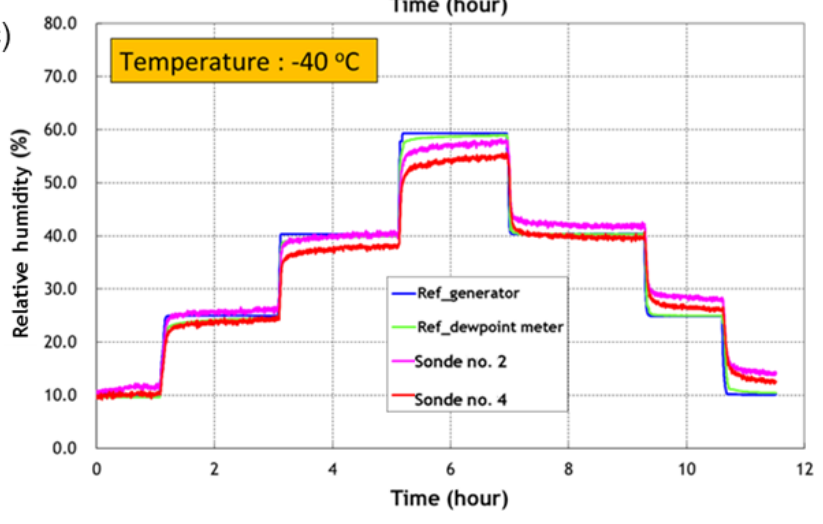

Figure 3. Humidity measurements by radiosonde humidity sensors and the reference humidity by the generator and the hygrometer at $-1,-20$, and $-40^{\circ} \mathrm{C}$.

room-temperature measurement. At $-40^{\circ} \mathrm{C}$, however, the measurements started to deviate from the standard, especially in the high-humidity ranges. The deviation increased as the temperature decreased, as shown by the measurement plot increasingly deviating from the standard plot. This implies that the sensitivity of the humidity sensors largely depend on the temperature.

Figure $5 \mathrm{a}$ shows the humidity measurements by radiosonde humidity sensors as a function of the reference humidity at each temperature. The corresponding deviation from the reference humidity is shown in Fig. 5b. From room temperature down to $-40^{\circ} \mathrm{C}$, the deviation was within $2 \% \mathrm{RH}$, but it increased to $10 \% \mathrm{RH}$ at $-60^{\circ} \mathrm{C}$ and further to (a)

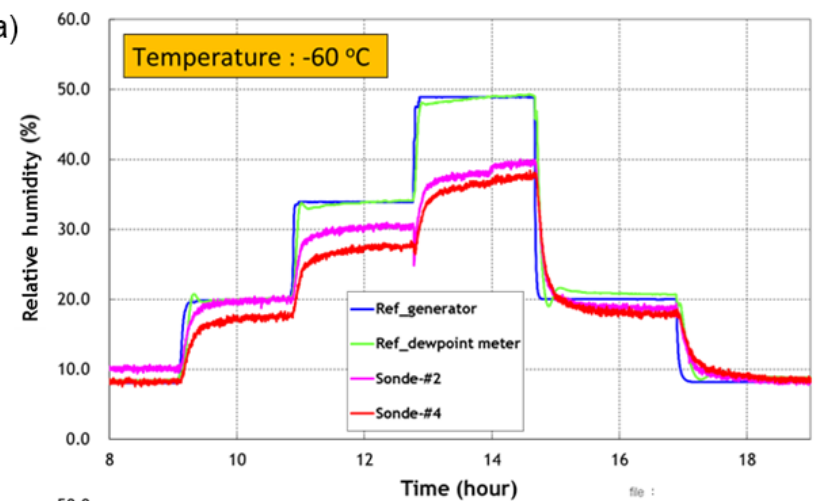

(b)

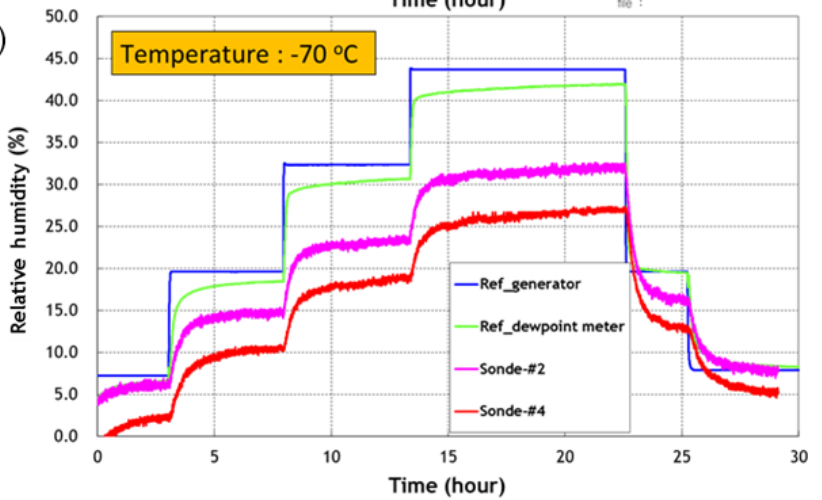

(c)

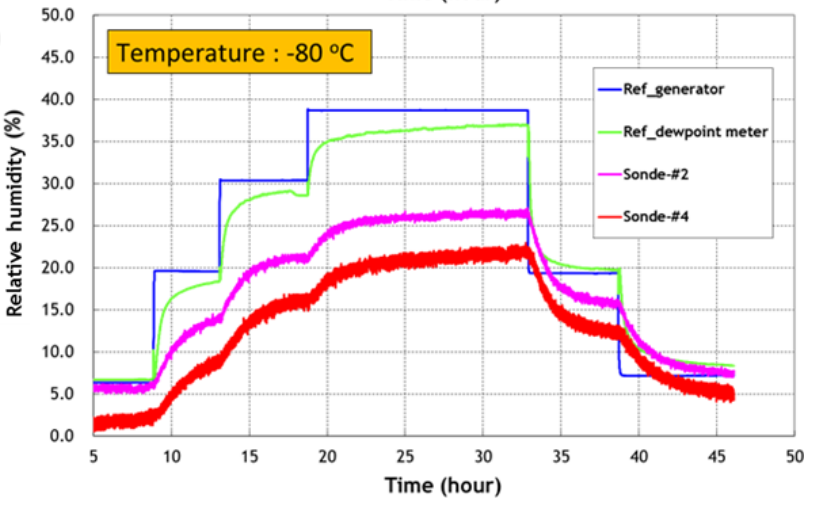

Figure 4. Humidity measurements by radiosonde humidity sensors and the reference humidity by the generator and the hygrometer at $-60,-70$, and $-80^{\circ} \mathrm{C}$.

$15 \% \mathrm{RH}$ at $-80^{\circ} \mathrm{C}$. Where, the measurement uncertainties were less than $1 \% \mathrm{RH}$ above temperature $-40^{\circ} \mathrm{C}$ and within $2 \% \mathrm{RH}$ at $-80^{\circ} \mathrm{C}$. During this evaluation of the radiosonde humidity sensors, the radiosonde temperature sensors, that are thermistors, are also calibrated through the comparison with the calibrated PRT in the test chamber at each temperature. Although the data for temperature sensors is not shown here, the calibration result is shown in Fig. 6a. The temperature calibration curves of the temperature and humidity sensors were obtained based on these measurements, as shown in Fig. 6. The calibration curve of the temperature sensors was expressed as $T^{\prime}=0.0086 \cdot T+0.2242$ in Fig. 6a, while the curve was $\mathrm{RH}^{\prime}=0.27 \cdot T+12.62$ (at $20 \% \mathrm{RH}$ ) and $\mathrm{RH}^{\prime}=0.37 \cdot T+14.15$ (at $40 \% \mathrm{RH}$ ) for the humidity sen- 
(a)

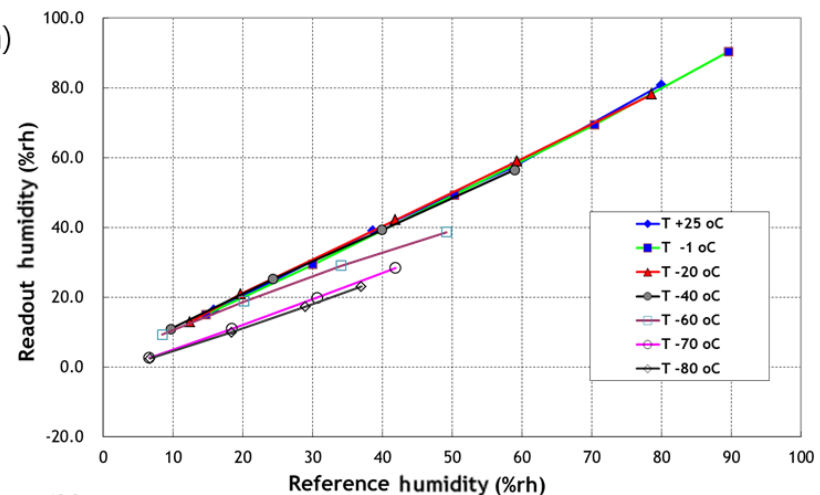

(b)

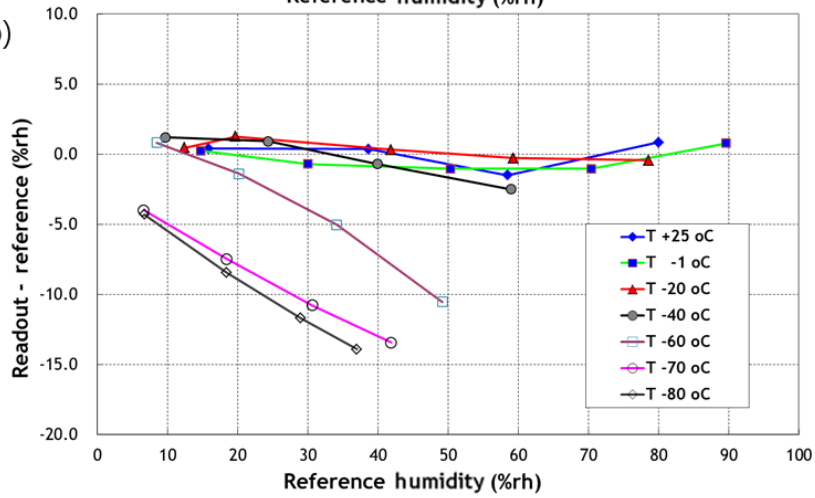

Figure 5. (a) The averaged measurement of relative humidity by two radiosonde humidity sensors and (b) the corresponding difference between the measurement and the reference humidity as a function of the reference humidity at varied temperature.

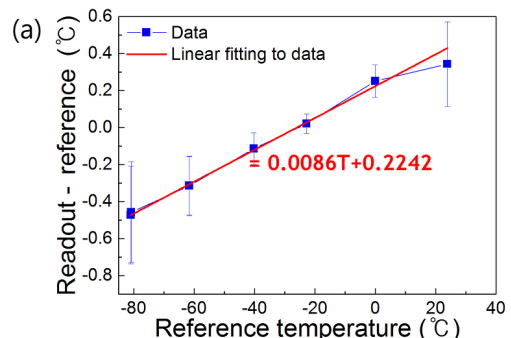

(b)

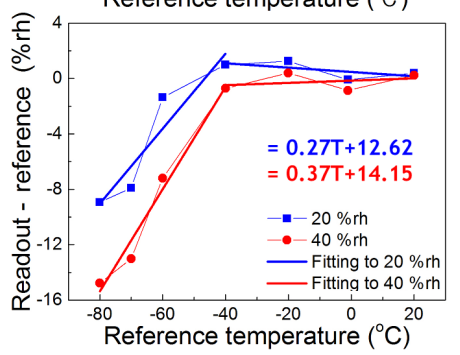

Figure 6. Calculated correction curves for (a) temperature and (b) humidity sensors as a function of the reference temperature. The data in (a) is the average of measurements by four radiosonde temperature sensors and data in (b) is the average of the measurements by two radiosonde humidity sensors.
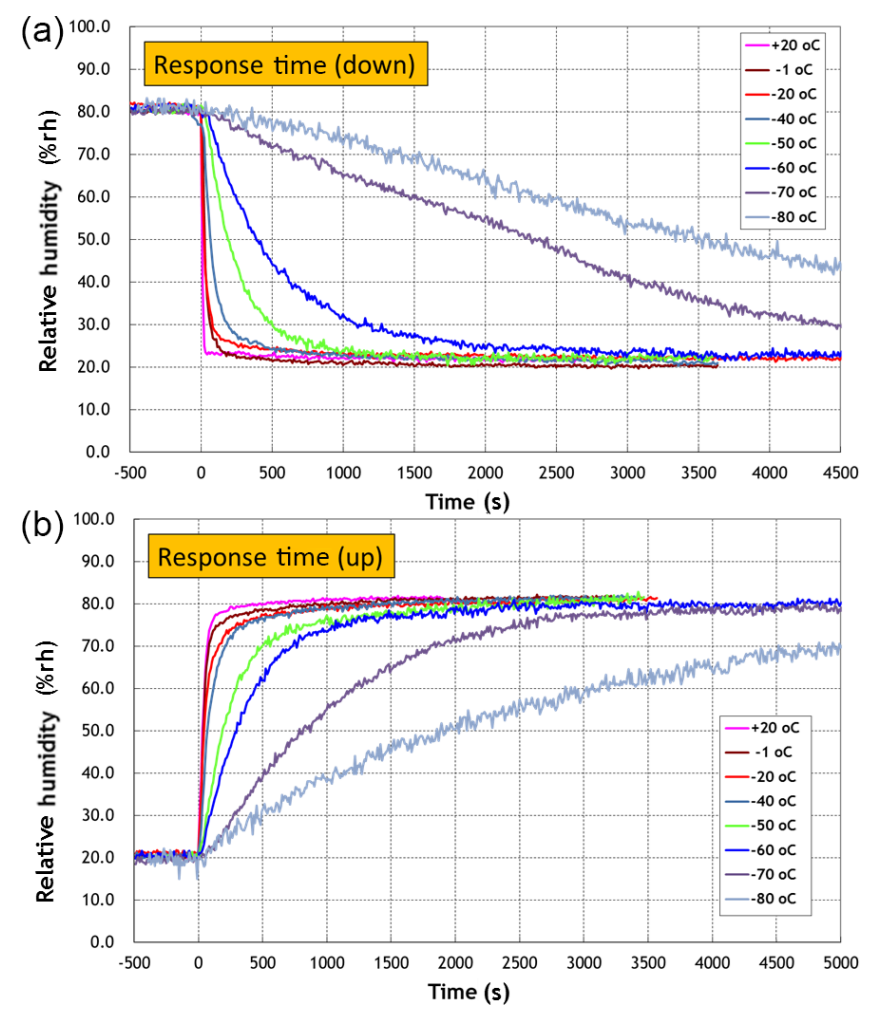

Figure 7. Response time of humidity sensors on radiosonde with decreasing (down, a) and increasing (up, b) humidity between $20 \% \mathrm{RH}$ and $80 \% \mathrm{RH}$ at various temperatures.

sors at $-40^{\circ} \mathrm{C}$ or lower in Fig. 6b. Where, the uncertainties were not considered because the number of sensors was small. The results in Figs. 5 and 6 are obtained by increasing the relative humidity. Although a hysteresis in the humidity measurement by sensors was observed when increasing and decreasing relative humidity, the hysteresis is not considered in Figs. 5 and 6.

\subsection{Temperature dependence of response time}

Since the actual radiosonde measures humidity with flying, at an average speed of $5 \mathrm{~m} \mathrm{~s}^{-1}$, the information of response time of sensor is very important for the correction of the measured values. Figure 7 shows the measured response time of the humidity sensors of the radiosonde with respect to temperature. The humidity was varied between $20 \% \mathrm{RH}$ and $80 \%$ RH with increasing and decreasing. Here, the humidity refers to the relative humidity as defined by the general definition using the saturation vapor pressure of water over the current phase of water (i.e. water or ice), not by the WMO definition using saturation vapor pressure of only water including supercooled water. In case of decreasing humidity, the response time was about $52 \mathrm{~s}$ at room temperature, and as the temperature decreased, it slowly increased from $53 \mathrm{~s}$ at $-1{ }^{\circ} \mathrm{C}$ to $73 \mathrm{~s}$ at $-20^{\circ} \mathrm{C}$. The response time sharply in- 
creased, starting from $-40^{\circ} \mathrm{C}$ at $116 \mathrm{~s}$, to $294 \mathrm{~s}$ at $-50^{\circ} \mathrm{C}$, to $452 \mathrm{~s}$ at $-60^{\circ} \mathrm{C}$, to $1207 \mathrm{~s}$ at $-70^{\circ} \mathrm{C}$ and further to $3150 \mathrm{~s}$ at $-80^{\circ} \mathrm{C}$. Additionally, a similar temperature dependency was observed during increasing humidity as shown in Fig. 7b. Note that the typical response time by the test chamber itself due to the adsorption/desorption of water molecules was faster than the response time of the humidity sensor at low temperatures.

\section{Conclusion}

The sensitivity characteristic and response time of radiosonde humidity sensors were investigated at low temperature, using developed ultralow-temperature humidity chamber which is based on two-pressure humidity generator. The sensitivity of the radiosonde sensors was measured up to $-80^{\circ} \mathrm{C}$, and it was confirmed that the temperature dependency of humidity characteristics was more than $15 \% \mathrm{RH}$. Based on this, calibration curves of the humidity sensor and the temperature sensor were obtained. The response time of humidity sensor from room temperature to $-40{ }^{\circ} \mathrm{C}$ slowly increased from 52 to $116 \mathrm{~s}$, and then rapidly increased to almost one hour at $-80^{\circ} \mathrm{C}$. Since the practical radiosonde is measured while flying at an average speed of $5 \mathrm{~m} \mathrm{~s}^{-1}$, the information on the response time is very important information for the correction of the measurement data. Evaluation of the radiosonde sensors on the ground by ultralow-temperature humidity chambers will improve the accuracy and reliability of the upper-air observation data.

Data availability. All data are originally produced by the authors through experiments and the data is only available in this paper.

Author contributions. BIC designed the humidity generator, conducted experiments, and wrote the manuscript. SWL analysed the data and wrote the manuscript. SBW and JCK constructed the humidity generator and conducted experiment. YGK designed experiments. SGY interfaced the humidity sensor with the humidity generator.
Competing interests. The authors declare that they have no conflict of interest.

Special issue statement. This article is part of the special issue "17th EMS Annual Meeting: European Conference for Applied Meteorology and Climatology 2017". It is a result of the EMS Annual Meeting: European Conference for Applied Meteorology and Climatology 2017, Dublin, Ireland, 4-8 September 2017.

Acknowledgements. This work was supported by the Korea Research Institute of Standards and Science under the project "Development of Measurement Standards Technology as National Infrastructure in Response to the Climate Change".

Edited by: Graziano Coppa

Reviewed by: Richard Högström and one anonymous referee

\section{References}

Choi, B. I., Kim, J. C., Woo, S. B.: Uncertainty of the KRISS Low Frost-Point Humidity Generator, Int. J. Thermophys., 33, 1559, https://doi.org/10.1007/s10765-012-1224-y, 2012.

GCOS: The GCOS Reference Upper-Air Network (GRUAN) 4 GUIDE, WMO, Geneva, Switzerland, 2013.

Mayer, C., Miller, W., Ripple, D., and Space, G.: Performance and validation tests on the NIST hybrid humidity generator, Int. J. Thermophys., 29, 1606-1614, 2008.

Nash, J., Oakley, T., Vomel, H., and Wei, L.: WMO Intercomparison of high quality radiosonde systems, WMO/TD-No. 1580, Yangjiang, China, 2011.

Sairanen, H., Heinonen, M., and Hogstrom, R.: Validation of a calibration set-up for radiosondes to fulfil GRUAN requirements, Meas. Sci. Technol., 26 105901-07, https://doi.org/10.1088/0957-0233/26/10/105901, 2015.

Wiederhold, P.: Water Vapor Measurement - Methods and Instrumentation, CRC Press, Boston, 1997.

WMO-BIPM: Measurement challenges for global observation systems for climate change monitoring, 30 March 2010, WMO/TDNo. 1557, Geneva, Switzerland, 2010. 